\title{
The Synthesis and characteristic study of transferrin-conjugated liposomes carrying brain-derived neurotrophic factor
}

\author{
Chen Jia-jun ${ }^{\mathrm{a}}$, Jin Mei-xiang ${ }^{\mathrm{b}}$, Zhu Shu-lai ${ }^{\mathrm{a}}, \mathrm{Li} \mathrm{Fei}^{\mathrm{a}}$, and XingYing ${ }^{\mathrm{a}}$ \\ ${ }^{a}$ Department of neurology, China-Japan Union Hospital, Jilin University, 126 Xiantai Street, \\ Changchun 130012, China \\ ${ }^{b}$ Department of neurology, Jilin province people's hospital, Changchun 130012, China, 130021
}

\begin{abstract}
This study aimed to establish a novel non-viral liposome vector delivering brain derived neurotrophic factor (BDNF) through the blood brain barrier. For this purpose, different water-oil ratios were tested to create liposomes for packaging the prophase synthesized plasmids encoding the BDNF proteins. In order to increase the targeted and peripheral circulation time, we connected the liposomes with transferrin (Tf) and a polyethylene glycol (PEG) long chain. The non-isotope method was used to measure the liposome envelopment ratio and ligand-binding ratio, and also to detect molecular biological features, such as particle size and stability. Tf-conjugated liposomes could be synthesized satisfactorily under the following conditions: the ratio of phospholipid to cholesterol was 1:1; the ratio of enter to plasmid was 100:1; oil phase was dichloromethane; the oil to water ratio was $4: 1$; the rotary evaporation temperature was $30^{\circ} \mathrm{C}$; the ultrasonic temperature was $10^{\circ} \mathrm{C}$; the ultrasonic time was $10 \mathrm{~min}$; and $10 \%$ trehalose was in the presence. Generated liposomes had a uniform circular shape and particle size distribution. In this experiment, we successfully established a new type of Tf-conjugated liposomes carrying the gene of BDNF and the study provides an experimental basis for the future.
\end{abstract}

Keywords: Brain derived neurotrophic factor, Tf-conjuaged, non-viral vector, liposome, transferrin

\section{Introduction}

Brain derived neurotrophic factor (BDNF) is a member of the family of neurotrophic factors. In 1982, BDNF was found in the brain of pigs for the first time. BDNF and its receptor are widely distributed in the central nervous system [1]. It is one of the most important neurotrophic factors in the brain, which maintains and promotes the growth and differentiation of neurons. It also plays an important role in the process of repair [2,3]. However, the expression of endogenous BDNF is low, whereas exogenous BDNF cannot go through the blood brain barrier due to its large molecular weight. How to carry exogenous BDNF into the intracranial area is a current research hotspot. Carrying by a viral vector is one of the means for gene therapy and has been studied by many scholars. However, its side effects are obvious, including increasing the risk of infection and leading to demyelination and

\footnotetext{
* Corresponding author: Xing Ying, Neurology Department of China-Japan Union Hospital, Jilin University, 126 Xiantai Street, Changchun 130012, China Tel: 86-0431-84995820; phone: 13844021603 Email: xingying1970@163.com
}

0959-2989/14/\$27.50 @ 2014 - IOS Press and the authors. 
immunogenicity in the central nervous system [4,5]. Hence, it is crucial to develop safe and efficient non-viral vectors. Liposome is a kind of non-viral vector that can deliver molecules such as DNA and drugs to the action sites, and it has been used to carry exogenous gene productions [6]. However, traditional liposomes are limited by low coating rates which hamper their efficiency of transfection into cells. Moreover, the liposome envelopment rate and drug loadings are usually obtained by the means of isotope labeling, which requires specific equipment to prevent radiation. It limits liposome generation in places where radioisotopes cannot be used. Researchers have explored the method of assembling liposomes [7,8], such as liposomes self-assembled from electrosprayed composite microparticles and from amphiphilic electrospun nanofibers. In this study, we tested different water-oil ratios to build liposomes, which packages the prophase synthesized $B D N F$ gene fused with a GFAP promoter. The liposomes were linked with transferrin and a PEG long-chain. We also created a new type of non-viral vector without isotope labeling, which could successfully carry exogenous $B D N F$ gene. It provides an experimental basis for in vivo targeted gene therapy in the future.

\section{Materials and Methods}

\subsection{Materials}

Two efficient transfected plasmids, pGFAP-BDNF and pCMV- BDNF, were constructed in our laboratory. Cholesterol formic acid ester chloride, chloroform, N, N - dimethyl ethylenediamine, phospholipids, DNaseI, Exonuclease III, and trehalose were all purchased from Sigma, USA. Methylene chloride, EDTA, POPC, DSPE-PEG-MAL and DSPE-PEG were all purchased from Avanti, USA. AgaroseCL-4B was from GE, USA. Tf, anhydrous ethanol, dimethyl sulfoxide, SDS, PicoGreen nucleic acid quantitative kit and BCA protein kit were all purchased from Invitrogen, USA.

\subsection{Preparation of C-cholesterol}

$2.25 \mathrm{~g}(5 \mathrm{mmol})$ of Cholesterol chloroformate was weighed and dissolved in $5 \mathrm{ml}$ of chloroform. It was then dried at $0^{\circ} \mathrm{C}$ in an ice bath. The excess $\mathrm{N}, \mathrm{N}$-dimethyl ethylenediamine chloroform solution was added in drops with stirring. The liquid was dried $(18 \mathrm{mmol}$ of $\mathrm{N}, \mathrm{N}$-dimethylethylenediamine was dissolved in $3 \mathrm{ml}$ chloroform and dried). A Rotary evaporator was used until the reaction was complete. The reaction was terminated with cholesterol chloroformate. The generated powder was recrystallized twice with absolute ethanol, and then purified and dried in vacuo.

\subsection{The synthetic and screening process of liposomes and determination of the liposome envelopment rate, oil type and oil phase ratio}

$0.6182 \mathrm{~g}$ of phospholipids and $0.4149 \mathrm{~g}$ of DC-Chol were weighed and dissolved with chloroform into a $25 \mathrm{ml}$ volume system. $1 \mathrm{ml}$ of phospholipid stock solution and $1 \mathrm{ml}$ of DC-chol stock solution were added into a round bottom tube and placed at in a dry rotary evaporator with the temperature set to $30^{\circ} \mathrm{C}$. Diethyl ether, chloroform and methylene chloride were selected as the organic phase, respectively. Appropriate water was added according to the water-oil ratio of 1:1, 1:2, 1:3, 1:4 and 1:5. $4 \mathrm{ml}$ of the organic phase solvent was added into the stock solution while rotary evaporation was kept operating. The products were vortexed for $5 \mathrm{~min}$. The compatibility of the two phases was monitored till a homogeneous opalescence phase was formed. A group of water-compatible phases were selected 
and placed in an ultrasonic bath for 30min. The oil and water phases were not stratified in order to determine the appropriate water-oil ratio.

\subsection{The proportion of phospholipids and cholesterol screening}

Chloroform was used as the organic phase to investigate the encapsulation efficiency of liposomes under different phospholipid /cholesterol ratios (1:0.5, 1:1, 1:2 and 1:3). Phospholipid and DC-Chol were added into a round bottom test tube or beaker according to the above ratios and then dried by a rotary evaporator. $4 \mathrm{ml}$ of chloroform and $1 \mathrm{ml}$ of plasmid solution were added and vortexed for $5 \mathrm{~min}$, followed by 5 min-ultrasound at different temperature. The organic solvent was dried in a rotary evaporator at room temperature. The aqueous phase was collected. $200 \mathrm{ul}$ of sample was added into $1 \mathrm{ml}$ water and then filtered using a $0.45 \mathrm{um}$ filter. $450 \mathrm{ul}$ of solution was added into a $10 \mathrm{kDa}$ MWCO ultrafiltration tube. Centrifugal ultrafiltration was performed at the speed of $3000 \mathrm{rpm}$ for $30 \mathrm{~min}$. The lower supernatant was collected to determine the concentration, and the encapsulation efficiency was calculated. The density of the purified plasmid (pCMV-BDNF or pGFAP-BDN) DNA with the high transformation levels was $1 \mathrm{mg} / \mathrm{ml}$ in a total volume of $4 \mathrm{ml}$. According to different $\mathrm{F}$ values of plasmid concentrations, the standard curve was calculated and the concentrations of free DNA, entrapment efficiency and particle size were measured.

\subsection{Synthesis conditions for liposomes screening and determination of liposomes}

$1 \mathrm{ml}$ of phospholipid stock solution and $1 \mathrm{ml}$ of DC-Chol stock solution were added into a test tube or beaker. The temperature of the rotary evaporator was set up at $20^{\circ} \mathrm{C}, 30^{\circ} \mathrm{C}$ and $40^{\circ} \mathrm{C}$ to dry samples, respectively. $4 \mathrm{ml}$ of chloroform was added to form $1 \mathrm{ml}$ plasmid aqueous phase. Liposomes were prepared under different conditions, including $4{ }^{\circ} \mathrm{C}, 10^{\circ} \mathrm{C}$ and $20^{\circ} \mathrm{C}$ of ultrasonic temperature and $2 \mathrm{~min}$, $5 \mathrm{~min}$ and $10 \mathrm{~min}$ of ultrasonic time. According to the instructions of PicoGreen nucleic acid quantitative kit, the encapsulation efficiency of liposomes was determined.

\subsection{Synthesis of Tf-conjugated liposomes}

\subsubsection{Synthesis of PEG-liposomes}

$0.4149 \mathrm{~g}$ of DC-Chol was weighted and dissolved in chloroform to a $25 \mathrm{ml}$ system. $33 \mathrm{mmol} / \mathrm{L}$ of DC-Chol was prepared. $259.71 \mathrm{mg}$ of POPC, $56.1 \mathrm{mg}$ of DSPE-PEG and 11.22mg of DSPE-PEG-MAL were accurately weighed and dissolved with chloroform to a final volume of $10 \mathrm{ml} .33 \mathrm{mmol} / \mathrm{L}$ of POPC, $1.65 \mathrm{mmol} / \mathrm{L}$ of DSPE-PEG and $0.33 \mathrm{mmol} / \mathrm{L}$ of DSPE-PEG-MAL were prepared. POPC chloroform solution was drawn. The DSPE-PEG chloroform, DSPE-PEG-MAL and DC-Chol chloroform solutions were mixed together to form a chloroform solution (385ul) and added into a beaker at room temperature. The solvent was dried in a rotary evaporator. $4 \mathrm{ml}$ of dichloromethane was added into $1 \mathrm{ml}$ of plasmid reconstitution solution $(1 \mathrm{mg} / \mathrm{ml})$, followed by 5 min-vortex and 5 min-ultrasound. Chloroform was evaporated at $30^{\circ} \mathrm{C}$ to obtain plasmid liposome solution. Similarly, the plasmid solution with an aqueous solution was used to generate liposome solution. The obtained plasmid liposomes were filtered through a $100 \mathrm{~nm}$ microporous membrane. The plasmid liposomes recovered were treated with Dnasei and Exonuclease III at $37^{\circ} \mathrm{C}$ for $1 \mathrm{~h}$. In the end, the reaction was stopped by EDTA. 


\subsubsection{Thiolated $T f$}

$25 \mathrm{mg}$ of Tf was weighted and added into $8 \mathrm{ml}$ of $1 \mathrm{~mol} / \mathrm{L}$ hydrochloric solution, mixing. Deionized water was added to a final volume of $50 \mathrm{ml} .1 \mathrm{~g}$ of catalyst was added into EDAC solution with stirring until the catalyst was completely dissolved. $0.5 \mathrm{ml}$ of pure mercaptoacetic acid was added into the obtained solution. $2 \mathrm{~mol} / \mathrm{L}$ of $\mathrm{NaOH}$ was used to adjust $\mathrm{pH}$ till $\mathrm{pH}$ was 5 . The reaction was performed in dark at room temperature for $5 \mathrm{~h}$. Samples are dialyzed at $10^{\circ} \mathrm{C}$ and at dark for once against $5 \mathrm{mmol} / \mathrm{L}$ hydrochloric acid, twice against $5 \mathrm{mmol} / \mathrm{L}$ hydrochloric acid and $1 \% \mathrm{NaCl}$, and then three times against $1 \mathrm{mmol} / \mathrm{L}$ hydrochloric acid. Dialysis buffer was changed every 2 hours. The samples were further concentrated to 3-4 $\mathrm{ml}$ by solid dispersion with PEG20000 around the dialysis bag, and then lyophilized at $-30^{\circ} \mathrm{C}$ and stored at $4^{\circ} \mathrm{C}$.

\subsubsection{Conjugation of Thiolated Tf and PEG- liposomes}

The PEG-liposomes was diluted to $80 \mathrm{ug} / \mathrm{ml}$ with sterile water, and then $250 \mathrm{ul}$ of this solution was mixed with $250 \mathrm{ul}$ of $18 \mathrm{mmol} / \mathrm{L}$ sodium sulfate. The PEG-liposomes solution and $2 \mathrm{ml}$ of thiolated Tf were pre-warmed at $55 \mathrm{C}$ for $15 \mathrm{~min}$. The Thiolated Tf solution was then added into the DNA solution at $100 \mathrm{ul} / \mathrm{s}$ with vortexing. The mixture was vortexed for another 30 seconds and incubated at room temperature for 30 minutes. The products were named as the Tf-DNA-PEG Nano-gold suspension.

\subsubsection{Determination of the Tf coupling ratio and analysis of the physical characteristics of Tf-liposomes}

The concentration of Tf - pCMV - BDNF - PEG, Tf - pGFAP - BDNF - PEG and Tf - $\mathrm{H}_{2} \mathrm{O}$ - PEG proteins were measured using a BCA protein quantitative kit and a spectrophotometer at OD562. The coupling rate of liposomes was then determined. In order to confirm the plasmid DNA had been wrapped into the interior of liposomes, $10 \mathrm{ul}$ of plasmid-carrying liposomes was mixed with $20 \mathrm{ul}$ of $0.5 \%$ SDS for cracking. The plasmid, the plasmid-carrying liposome and liposome lysis plasmid were detected by electrophoresis using a $0.8 \%$ agarose gel. The electrophoresis result was observed using ultraviolet transillumination.

\subsubsection{The electron microscope of Tf-PLs}

The Tf-pCMV-BDNF-PEG, Tf-pGFAP-BDNF-PEG or Tf- $\mathrm{H}_{2} \mathrm{O}-\mathrm{PEG}$ suspension was added into 50ul vinyl alcohol formal copper network and fixed about $3 \mathrm{~min}$. Excess liquid was absorbed with absorbent paper. $1 \%$ uranyl acetate of copper was added to the copper grid, standing for $2 \mathrm{~min}$. Excess liquid was absorbed again. The samples were air dried for $1 \mathrm{~h}$, and then placed under an electron microscope to observe the shape and size distribution of liposomes.

\section{Results}

\subsection{Oil type and oil phase ratio selection}

The experimental results showed that a homogeneous phase was formed when the ratio of water to chloroform or methylene chloride was 1:4. Thus, chloroform or methylene chloride is a preferable organic solvent. 


\subsection{The synthetic process and prescription screening of liposome and determination of the liposome envelopment rate}

Chloroform was used as the organic phase. Different phospholipid and cholesterol ratios (1:0.5, 1:1, $1: 2$ and 1:3) were investigated. The encapsulation efficiency of liposomes was calculated and the phospholipid and cholesterol feed ratio was determined. different $\mathrm{F}$ values of plasmid concentrations. The standard curve was calculated with the equation: $Y=15.024 \mathrm{X}+140.3931$. The concentration of free DNA and entrapment efficiency as well as the particle size were measured. According to the kit instructions, PicoGreen nucleic acid was used to quantify the encapsulation efficiency of liposome. When the rotary evaporator temperature was at $20^{\circ} \mathrm{C}$ and $30^{\circ} \mathrm{C}$, the liposome encapsulation efficiency was $55.32 \%$ and $87.45 \%$, respectively. When the temperature was $40^{\circ} \mathrm{C}$, the evaporated solution had a large number of bubbles. Hence, liposomes were prepared at $30^{\circ} \mathrm{C}$. When the ultrasonic temperature was $4^{\circ} \mathrm{C}$, water couldn't be fully mixed with oil. In contrast, water could be fully mixed at $10^{\circ} \mathrm{C}$, and the particle size was $250 \mathrm{~nm}$. At $20^{\circ} \mathrm{C}$, the particle size was $450 \mathrm{~nm}$. Different ultrasonic time was tested. Oil failed to be thoroughly mixed with water after 2 min-ultrasound. The particle size was $248 \mathrm{~nm}$ and $452 \mathrm{~nm}$ after $5 \mathrm{~min}$ - and 10 min-ultrasound, respectively. By comparison, $30{ }^{\circ} \mathrm{C}$ was selected as the liposomes rotational temperature and $10^{\circ} \mathrm{C}$ and $5 \mathrm{~min}$ were chosen as the appropriate ultrasound temperature and time. Given the above conditions, the encapsulation efficiency was high and smaller particle size and uniform liposomes could be obtained. Different concentrations of trehalose were tested in the liposome size distribution analysis under circumstances described above. The results showed that only $10 \%$ of trehalose was suitable to be used as stabilizer, with which the particle sizes of liposomes render a standard distribution. Thus, Tf-conjugated liposomes could be synthesized satisfactorily under the following conditions: the phospholipid/cholesterol ratio was 1:1; the enter/plasmid ratio was 100:1; dichloromethane was used as the oil phase; the oil/water ratio was $4: 1$; the rotary evaporation temperature was $30^{\circ} \mathrm{C}$; the ultrasonic temperature was $10^{\circ} \mathrm{C}$; the ultrasonic time was $10 \mathrm{~min}$; and $10 \%$ trehalose was in the presence.

\subsection{Synthesis of Tf-conjugated liposomes}

\subsubsection{Synthesis of PEG-liposomes}

Agarose gel electrophoresis was performed to detect plasmid DNA wrapped by liposomes and unwrapped DNA which was degraded by nucleases (Fig. 1). The figure showed that the plasmid DNA wrapped by liposomes moved slower in the agarose gel than the unwrapped DNA.

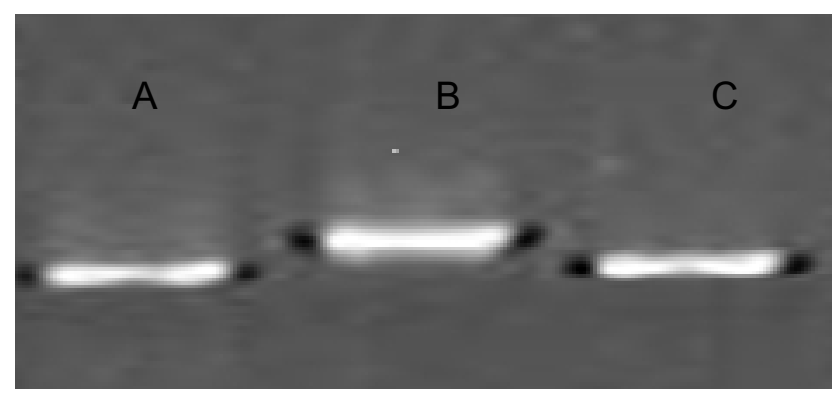

Fig.1 The electrophoresis of liposomes From L-R: A: unwrapped plasmid DNA; B : wrapped plasmid DNA; C : unwrapped plasmid DNA 


\subsubsection{Determination of the Tf coupling ratio}

The values of the standard proteins were 1:0, 2:0.137, 3:0.270, 4:0.432, 5:0.554 and 6:0.662. The measured values of the Tf-pCMV-BDNF-PEG eluent, which went through the column at different stages, were $0,0.081,0.112,0.131,0.132,0.120,0.334,0.530,0.553,0.542,0.131,0.221,0.232$, 0.122 and 0.02 . The measured values of the Tf-pGFAP-BDNF-PEG eluent, which went through the column at different stages, were $0,0.02,0.122,0.344,0.522,0.564,0.532,0.191,0.201,0.232,0.222$, $0.112,0.101,0.08$ and 0.04 . The measured values of the $\mathrm{Tf}_{-} \mathrm{H}_{2} \mathrm{O}-\mathrm{PEG}$ eluent, which went through the column at different stages, were $0,0.01,0.121,0.155,0.321,0.532,0.576,0.542,0.111,0.321,0.232$, $0.121,0.110,0.09$ and 0.01 .The standard curve was calculated according to $\mathrm{Y}=6.7471 \mathrm{X}+0.0051$. The coupling rates of $\mathrm{Tf}$ thiolated with PEG-liposomes were $51.75 \%$ for Tf-pCMV-BDNF-PEG, $52.10 \%$ for Tf-pGFAP-BDNF-PEG and $51.56 \%$ for $\mathrm{Tf}-\mathrm{H}_{2} \mathrm{O}-\mathrm{PEG}$, respectively. The three liposome elution curves after coupling were showed in Fig.2-4. According to the figure, the first peak should be Tf connected with liposomes and the second peak might be free Tf. The peaks showed particle size. The first peak detected at 400nm indicated Tf-pCMV-BDNF-PEG (76nm), Tf-pGFAP-BDNF-PEG(74nm) and Tf- $\mathrm{H}_{2} \mathrm{O}-\mathrm{PEG}(69 \mathrm{~nm})$. The values of the three PDI were 0.221 for Tf-pCMV-BDNF-PEG, 0.219 for Tf-pGFAP-BDNF-PEG and 0.198 for Tf- $\mathrm{H}_{2} \mathrm{O}-\mathrm{PEG}$, respectively (Fig. 5-7). The second peak $(200 \mathrm{~nm})$ showed not-uniformly distributed liposome size, and PDI $>0.8$. Therefore, the first peak suggests Tf-conjugated liposomes.

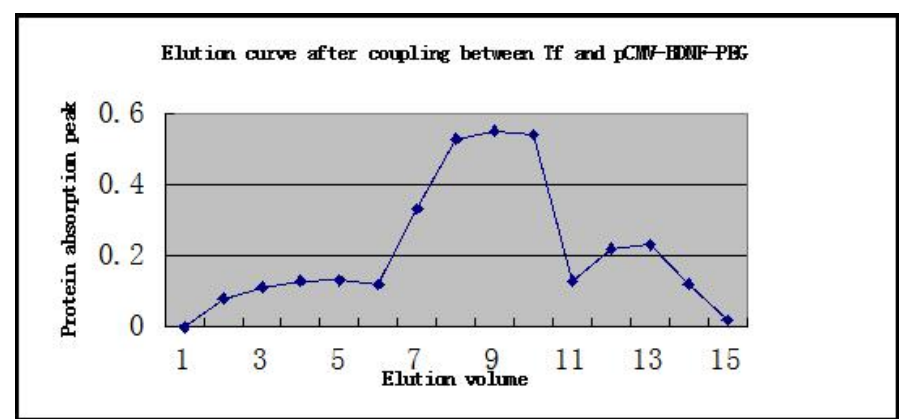

Fig.2 Elution curve after coupling of Tf and pCMV-BDNF-PEG X -axis means elution volume, Y-axis shows the protein absorption peak

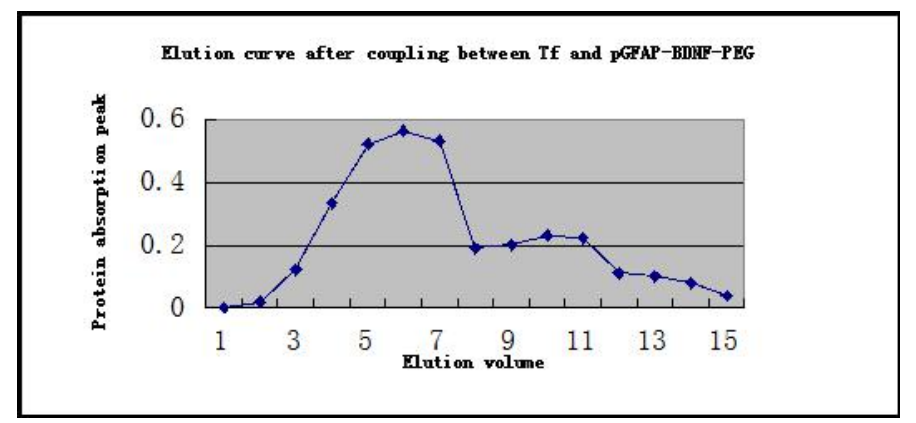

Fig.3 Elution curve after coupling of Tf and pGFAP-BDNF-PEG X -axis means elution volume, Y-axis shows the protein absorption peak 


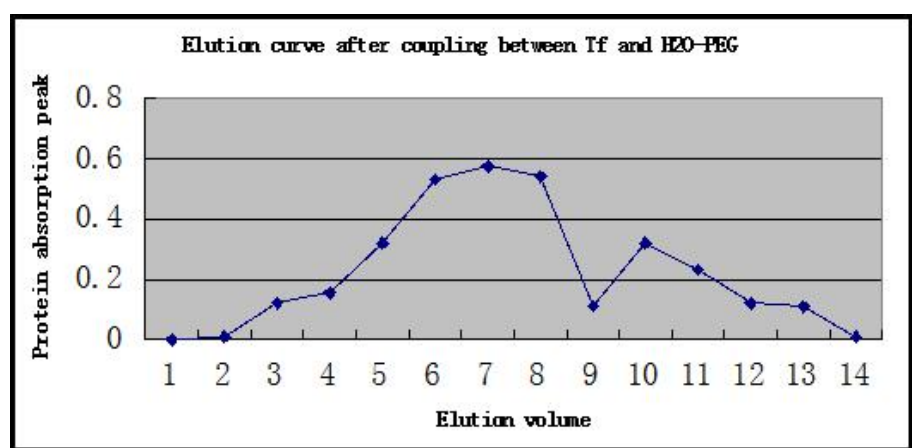

Fig.4 Elution curve after coupling of $\mathrm{Tf}$ and $\mathrm{H}_{2} \mathrm{O}-\mathrm{PEG}, \mathrm{X}$-axis means elution volume, $\mathrm{Y}$-axis shows the protein absorption peak

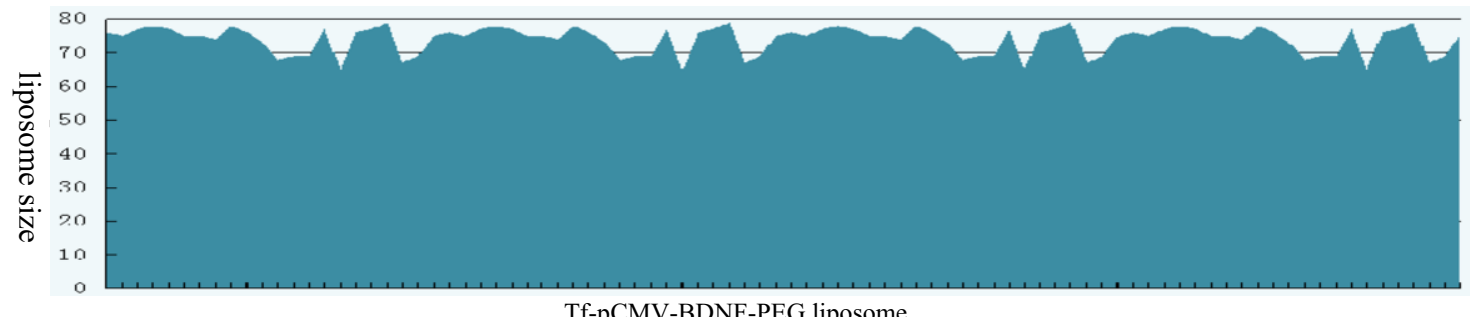

Fig.5 Tf-pCMV-BDNF-PEG size distribution, X -axis means Tf-pCMV-BDNF-PEG liposome, Y-axis means liposome size

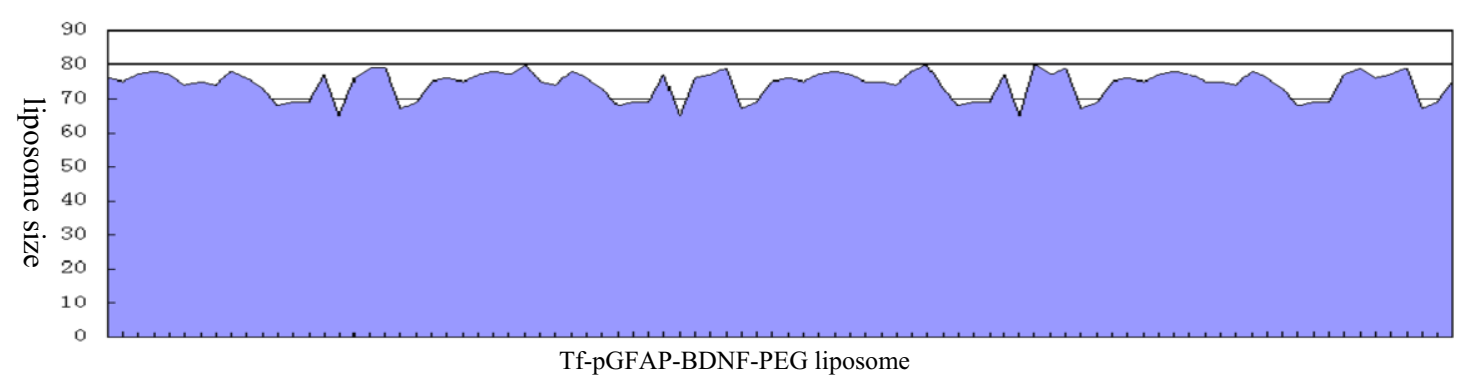

Fig.6 Tf-pGFAP-BDNF-PEG size distribution, X -axis means Tf-pGFAP-BDNF-PEG liposome, Y-axis means liposome size

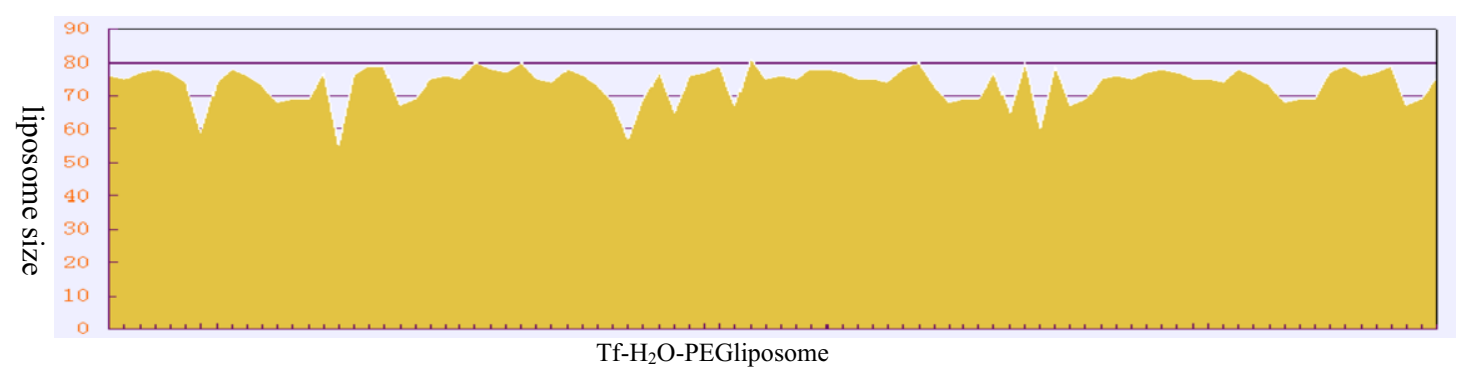

Fig.7 Tf- $\mathrm{H}_{2} \mathrm{O}-\mathrm{PEG}$ size distribution, $\mathrm{X}$-axis means Tf- $\mathrm{H}_{2} \mathrm{O}-\mathrm{PEG}$ liposome, $\mathrm{Y}$-axis means liposome size 


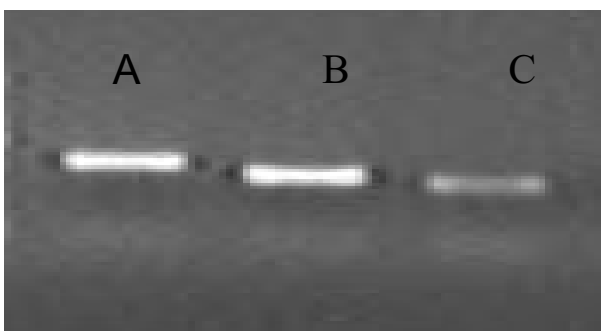

Fig.8 The agarose gel electrophoresis result of Tf-pCMV-BDNF-PEG (From L-R : Marker: D15000, wrapped DNA, plasmid DNA, released DNA)

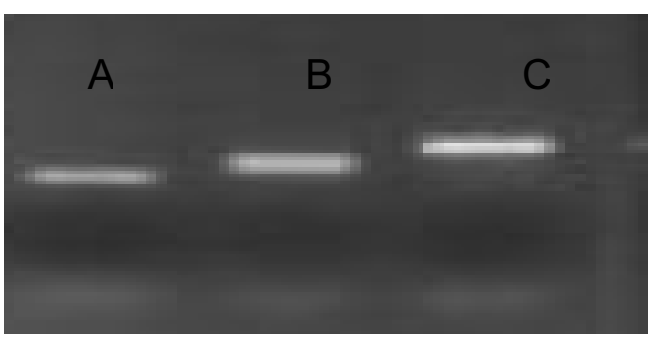

Fig.9 The agarose gel electrophoresis result of Tf-pGFAP-BDNF-PEG(From L-R : Marker: D15000, released DNA, plasmid DNA, wrapped DNA)

\subsubsection{Analyze the physical characteristics of Tf-liposomes}

As shown in Figure 8-9, most of DNA encapsulated by liposomes remained inside of the vesicle and could not migrate in an agarose gel. After being treated with the SDS detergent, liposomes were broken-down and the DNA inside the plasmid was released into the solution without being impaired. Liposomes were placed at $4^{\circ} \mathrm{C}$ for $1 \mathrm{~h}, 6 \mathrm{~h}$ and $24 \mathrm{~h}$ to detect the stability. Condensation conditions in PBS were then observed. No condensation phenomenon was detected, indicating that the stability of synthetized liposomes meets the requirement of the experiment.

\subsubsection{Tf-PLs observed using an electron microscope}

Tf-pCMV-BDNF-PEG, Tf-pGFAP-BDNF-PEG and Tf- $\mathrm{H}_{2} \mathrm{O}-\mathrm{PEG}$ were placed under an electron microscope to observe the form and liposome size distribution (80KV, 30000) (Fig.10-12). The figures showed that compared with $\mathrm{Tf}-\mathrm{H}_{2} \mathrm{O}$ - PEG, synthesized Tf - pCMV - BDNF - PEG and Tf - pGFAP BDNF had a uniform circular shape and particle size distribution.

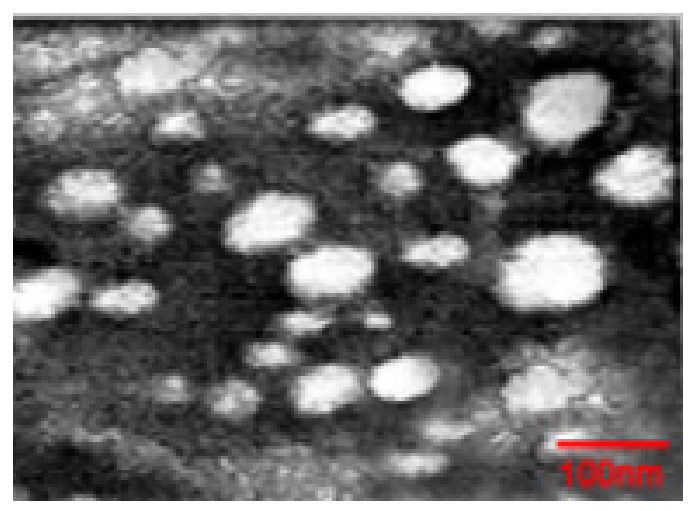

Fig.10 Tf-pCMV-BDNF-PEG observed using an electron microscope e,80KV,30000 


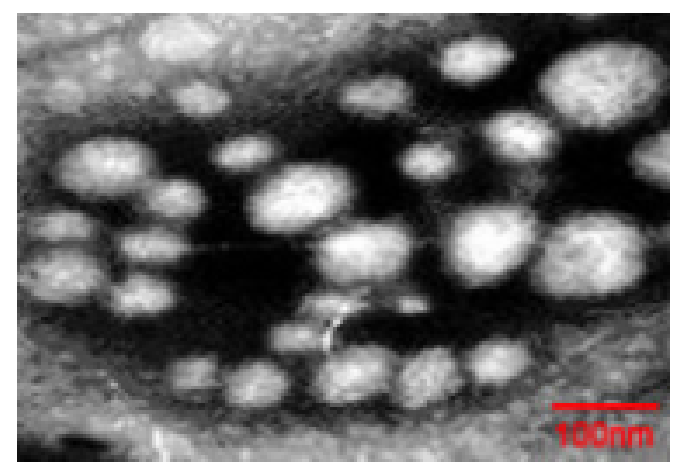

Fig.11 Tf-pGFAP-BDNF-PEG observed using an electron microscope, $80 \mathrm{KV}, 30000$

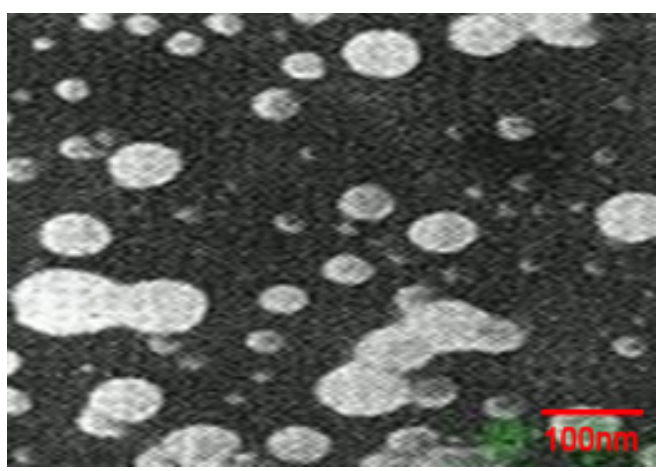

Fig.12 Tf- $\mathrm{H}_{2} \mathrm{O}-\mathrm{PEG}$, observed using an electron microscope, $80 \mathrm{KV}, 30000$

\section{Discussion}

As a member of the family of neural nutrients, BDNF plays an important role in many aspects, such as promoting the growth and differentiation of neurons and damage repair in the central nervous system. Due to the presence of the blood-brain barrier, it is difficult to put exogenous BDNF into the brain, and the secretion of endogenous BDNF is not enough to play a significant biological role [9]. How to carry BDNF through the blood brain barrier becomes a research hotspot. Currently, the direct lateral ventricle injection and using a virus vector are main approaches for treatment [10]. However, the side effects such as the invasive or viruses immunogenicity limit its broad application [11]. Yeast two-hybrid bait vectors and pTAT prokaryotic expression vectors are better, but the expression of BDNF failed to meet research needs due to the low expression levels of these vectors and strict expression requirement [12]. In recent years, some scholars try to use liposomes as a kind of non-virus vector to carry target genes to penetrate the blood brain barrier [13]. Liposomes are made from natural biodegradable lipid bilayer which is similar to animal cell membrane structure. Due to its nonimmunogenicity and low toxicity, it can avoid triggering the host immune response. Compared with direct DNA, nanoparticles of liposomes can provide an internal space to target genes and play a better effect in vivo [14]. The outer surface of liposomes can connect with targeting ligands to form targeted liposomes and complete the transfer function. Thus, molecular-weight polymer and cationic liposome has the potential to replace the viral vector. However, it has to overcome several common limitations such as low liposome package space, short life cycle, easily broken, etc. 
In order to synthesize effective liposomes, we investigated different phospholipid and cholesterol ratios (1:0.5, 1:1, 1:2 and 1:3), calculated the encapsulation efficiency of the liposomes and determined the favorable phospholipid/cholesterol feed ratio. Through comparison, Tf-conjuated liposomes were found to achieve satisfactory synthesis under the following conditions: the phospholipid/cholesterol ratio was $1: 1$; the ester/plasmid ratio was 100:1; dichloromethane was used as oil phase; the oil/water ratio was $4: 1$; the rotary evaporation temperature was $30^{\circ} \mathrm{C}$; the ultrasonic temperature and time were $10^{\circ} \mathrm{C}$ and $10 \mathrm{~min}$, respectively; and $10 \%$ trehalose was in the presence. GPAF promoter can lead to expression of specific target genes in neurons cells and astrocytes. In order to increase targeted combination with central neurons, in the previous experiments, we successfully constructed the pCMV - BDNF plasmid using genetic engineering technology, and further generated the pGPAF - BDNF expression vector, which can be transfected into cells with the recombinant plasmid. Using the above method and under experimental conditions, the coating rate of liposomes was higher $(52 \%)$ and uniform nano liposomes with smaller particle size $(<100 \mathrm{~nm})$ were generated. The liposomes were observed under an electron microscope. They had a uniform circular shape and particle size distribution. Specific proteins should be connected and the cycle time of peripheral blood circulation needs to be extended to enable the synthesized liposomes to effectively arrive the brain tissue from peripheral blood circulation. Transferrin (Tf) belongs to the class of iron-binding proteins. It has become a focus object in science since its serum transferring function was discovered 40 years ago [15]. Tf has a 670 to 700 amino acid polypeptide chain with a molecular weight of $80 \mathrm{KDa}$. Its isoelectric point is about 5.6-5.8 [16]. Tf is used as a carrier or targeting ligand. It can be linked to liposomes through a combination with proteins and has been applied in the transport of anticancer drugs $[17,18]$. Tf-conjuaged liposome chemotherapy drugs have been widely used and they have characteristics like low toxicity, long cycle and cell-specific targeting. In a study, liposomes were conjugated with Tf and leukemia HL60 cells and the conjugated liposomes were cultured and investigated. The results showed that the liposomes binding to specific cells were delivered into cells in vivo by receptor-mediated endocytosis [19]. Organs such as liver, spleen, lung, and capillary endothelial cells of blood brain barrier are relatively rich of $\mathrm{Tf}$ receptor. $\mathrm{Tf}$ targeting PEG-2000 lipid surface exhibits a longer circulation time and lower absorption. It has been reported that the blood half-life of PEG-liposomes made by this method was extended up to $90 \mathrm{~h} \mathrm{[20].}$

Liposome stability is the basis of guaranteeing the follow-up test. In the present study, liposomes were placed at $4^{\circ} \mathrm{C}$ for $1 \mathrm{~h}, 6 \mathrm{~h}$ and $24 \mathrm{~h}$ and then condensation conditions in PBS were observed. No condensation phenomenon was detected, indicating that the stability of synthesized liposomes meets the needs of the experiment.

\section{Conclusions}

This experiment successfully built a new kind of non-virus gene carrier by measuring its biological characteristics. The carrier had a long chain of PEG liposomes whose size was only about $100 \mathrm{~nm}$. The BDNF genes were packaged into the interior of the nanoparticles liposomes. The neurons cell-specific promoter GFAP replaced CMV. At the same time, Tf was coupled to the end of the long chain of PEG on the surface of liposomes. It has dual targets in the process of transportation and plays a role in the body by stimulating cell membrane receptors. The study provides an experimental basis for in vivo targeted therapy in the future. 


\section{Acknowledgments}

This work was supported in part by grants from Ji-lin province development and reform commission of China (No.JF2012C008-3)

\section{References}

[1] Y. Zhang and W.M. Pardridge, Delivery of $\beta$-galactosidase to mouse brain via the blood-brain barrier transferrin receptor, Journal of Pharmacology and Experimental Therapeutics 313 (2005), 1075-1081.

[2] K. Uchida, H. Nakajima, T. Hirai, T. Yayama, K. Chen, A.R. Guerrero, W.E. Johnson and H. Baba. The retrograde delivery of adenovirus vector carrying the gene for brain-derived neurotrophic factor protects neurons and oligodendrocytes from apoptosis in the chronically compressed spinal cord of twy/twy mice, Spine (Phila Pa 1976) 37 (2012), 2125-2135.

[3] R. Li, T. Liang, L. Xu, N. Zheng, K. Zhang and X. Duan, Puerarin attenuates neuronal degeneration in the substantia nigra of 6-OHDA-lesioned rats through regulating BDNF expression and activating the Nrf2/ARE signaling pathway, Brain Res. 1523 (2013), 1-9.

[4] A. Buttner, Review: The neuropathology of drug abuse, Neuropathol. Appl. Neurobiol. 37 (2011), 118-134.

[5] S. Brown, M. Kim and C. Mitchell, Inskip HTwenty-five year mortality of a community cohort with schizophrenia, Br. J. Psychiatry 196 (2010), 116-121.

[6] S. Ganly, S.O. Hynes, F. Sharif, A. Aied, V. Barron, K. McCullagh, J. McMahon, P. McHugh, J. Crowley, W. Wang, T. O'Brien and U. Greiser, Liposomal surface coatings of metal stents for efficient non-viral gene delivery to the injured vasculature, J. Control. Release. 167 (2013), 109-119.

[7] D.-G. Yu, J.-H. Yang, X. Wang et al., Liposomes self-assembled from electrosprayed composite microparticles, Nanotechnology 23 (2012), 105606.

[8] D.-G. Yu, C. Branford-White, G.R. Williams et al., Self-assembled liposomes from amphiphilic electrospun nanofibers, Soft. Matter. 7 (2011), 8239-8247.

[9] X. Fan, E.Y. Liu, O. Freudenreich, J.H. Park, D. Liu and J. Wang, Higher white blood cell counts are associated with an increased risk for metabolic syndrome and more severe psychopathology in non-diabetic patients with schizophrenia, Schizophr. Res. 118 (2010), 211-217

[10] W.R. Schabitz, T. Steigleder and C.M. Cooper-Kuhn, Intravenous brain-derived neurotrophic factor enhances poststroke sensorimotor recovery and stimulates neurogenesis, Stroke 38 (2007), 2165-2172.

[11] C.S.V. Bartheld and J.E. Johnson, Target-derived BDNF is essential for the survival of developing neurons in the isthmooptic nucleus, J. Comp. Neurol. (S0021-9967) 433 ( 2001), 550-564.

[12] L.S. Zweifel, R. Kuruvilla and D.D. Ginty, Functions and mechanisms of retrograde neurotrophin signaling, Nat. Rev. Neurosci. 6 (2005), 615-625.

[13] E. Golden, A. Emiliano and S. Maudsley, Circulating brain-derived neurotrophic factor and indices of metabolic and cardiovascular health: Data from the baltimore longitudinal study of aging, PLoS One 5 (2010), e10099.

[14] M.O. Krebs, O. Guillin and M.C. Bourdell, Brain derived neurotrophic factor (BDNF) gene variants association with age at onset and therapeutic response in schizophrenia, Mol. Psychiatry. 5 (2000), 558-562.

[15] T. Toda, Y. Momose and M. Murata, Toward identification of susceptibility genes for sporadic Parkinson's disease, J. Neurol. 250 (2003), 40-43.

[16] M. Neves-Pereira, E. Mundo and P. Muglia, The brain-derived neurotrophic factor gene confers susceptibility to bipolar disorder: Evidence from a family-based association study, Am. J. Hum. Genet. 71 (2002), 651-655.

[17] J. Kim, K. Inoue and J.A. Ishii, MicroRNA feedback circuit in midbrain dopamine neurons, Science 317 (2007), $1220-1224$

[18] T. Nishida, T. Arii and A. Takaoka, Three-dimensional, computer-tomographic analysis of membrane proteins (TrkA, caveolin, clathrin) in PC12 cells, Acta. Histochem. Cytochem. 40 (2006), 93-99.

[19] A.J. Weber, S. Viswana' than and C. Ramanathan, Combined application of BDNF to the eye and brain enhances ganglion cell survival and function in the cat after optic nerve injury, Invest. Ophthalmol. Vis. Sci. 51 (2010), 327-334.

[20] Y. Sun and Y. Zhao, Enhanced pharmacokinetics and anti-tumor efficacy of PEGylated liposomal rhaponticin and plasma protein binding ability of rhaponticin, J. Nanosci. Nanotechnol. 12 (2012), 7677-7684. 